DOI 10. 18307/2017. 0125

(c) 2017 by Journal of Lake Sciences

\title{
黄河龙门段商周转折时期的古洪水事件及气候背景
}

\author{
石彬楠, 黄春长 ${ }^{* *}$, 庞奖励, 查小春, 周亚利, 张玉柱, 刘雯瑾 \\ ( 陕西师范大学旅游与环境学院, 西安 710062)
}

\begin{abstract}
摘 要: 通过野外观察研究, 在黄河中游晋陕峡谷龙门段乡宁-韩城大桥西端支沟内, 发现了全新世古洪水滞流沉积物. 通过野外观察和室内实验分析,证明它们是黄河特大洪水悬移质泥沙在高水位滞流环境下的沉积物, 记录了黄河晋陕峡 谷段一期 4 次特大古洪水事件. 通过地层学对比分析和光释光测年, 确定这 4 次洪水发生在全新世中期-晚期转折阶段, 即我国历史上商代末期-西周初期的气候突变转型期. 利用 “古洪水滞流沉积物厚度含沙量法” 恢复古洪水洪峰水位, 运 用 HEC-RAS 模型估算出 4 次古洪水事件洪峰流量介于 $46280 \sim 48800 \mathrm{~m}^{3} / \mathrm{s}$ 之间. 这些成果为黄河中游地区的防洪减灾、 水资源开发利用、流域生态环境综合治理等方面提供了可靠的超长尺度水文数据. 这为深人理解黄河流域水文系统对于 全球变化的响应规律提供了新的证据.
\end{abstract}

关键词: 古洪水;商末;滞流沉积物;水文学;黄河

\section{Palaeoflood events and climate change at the turning time from the Shang to Zhou Dy- nasty in the Longmen reach of the Yellow River}

SHI Binnan, HUANG Chunchang ${ }^{* *}$, PANG Jiangli, ZHA Xiaochun, ZHOU Yali, ZHANG Yuzhu \& LIU Wenjin

(College of Tourism and Environmental Sciences, Shaanxi Normal University, Xi' an 710062, P.R.China)

\begin{abstract}
Palaeoflood slackwater deposits (SWD) of the Holocene and paleoflood indicators were interbeddedly found within the cliff riverbanks at Xianghanqiao profile in the Longmen reach of the Yellow River. Paleoflood SWD was identified by a variety of sedimentological criteria during field investigations and laboratory analysis. A set of four SWD records four paleoflood events individually. These slackwater deposits recorded the extraodinary floods happened between 3200-2800 a B.P. on the Yellow River, by using Optically Stimulated Luminescence dating method in combination with pedostratigraphy correlations. This indicated that the extraordinary floods happened during the dynasties from the Shang to the Western Zhou in Chinese history. The flooding peak stages were estimated with the sediment concentration and the depositional depths of the SWD. The estimated results indicated that the paleoflood peak discharges were between 46280 and $48800 \mathrm{~m}^{3} / \mathrm{s}$ by using HEC-RAS model. The results provided an important basis for this regional flood control and disaster mitigation project, water resource management, and comprehensive treatment of the ecological environment.
\end{abstract}

Keywords: Paleoflood; Shang dynasty; slackwater deposits; hydrology; Yellow River

黄河中游是我国人类文明的发祥地,全新世以来黄河中游的气候水文环境变化成为许多科学家研究的 热点. 古洪水水文学通过地貌学、沉积学、年代学和水文学等多学科的交叉,对古洪水滞流沉积物 ( slackwater deposits,即 SWD) 进行系统的研究,利用多种方法恢复古洪水事件洪峰水位,采用水力学模型推求古洪水流 量,进而获得远超历史调查洪水重现期的河流万年尺度洪水水文数据, 从而解决了设计洪水频率计算中因 数据序列长度不足以及代表性缺乏等问题 ${ }^{[1-4]}$. 古洪水作为河流超长尺度洪水信息, 其研究意义不仅局限于 改善设计洪水,而且对于理解、认识河流的发育史、古气候、古地貌和古生态环境以及全球变化的影响等也

* 国家自然科学基金项目 (41471071) 资助. 2015-12-18 收稿; 2016-05-10 收修改稿. 石彬楠( 1992 ), 男, 硕士; E-mail: binnanshi@163.com.

** 通信作者;E-mail: cchuang@ snnu.edu.cn. 
有相当重要的价值 ${ }^{[2]}$.

黄河的洪水灾害问题由来已久,在全球变暖和环境恶化的背景之下,黄河流域水资源缺乏问题日益突 出. 在黄河水资源和水能源开发、洪水灾害管理等工作中, 都亟需掌握超长尺度洪水水文数据资料 ${ }^{[3-4]}$. 通过 对黄河中游晋陕峡谷段的野外考察, 在多个地点发现了特大洪水高水位滞流环境下的悬移质沉积层剖面, 综合野外地层对比、新技术测年和沉积学鉴别特征，以及室内实验分析，确定为全新世时期古洪水 SWD 剖 面. 本文就乡宁-韩城大桥西端的支流沟口内发现的一组 4 层古洪水滞流沉积层进行深人研究, 为该地区超 长尺度洪水水文学研究提供了可靠的依据; 同时, 这种罕见的极端性的环境事件对于揭示黄河流域区域水 文过程对全球变化的响应规律,也具有非常重要的科学意义.

\section{1 研究区概况}

黄河到达内蒙古河套盆地之后, 从喇啉湾进入鄂尔多斯高原, 以近南北走向穿越黄土高原, 然后出龙门 流人汾渭盆地. 这一以流域界定的狭长地貌单元属于黄河中游地段, 以峡谷地貌为主要特征, 称之为晋陕峡 谷 (图 1). 该段北起内蒙古托克托河口镇, 南至山西省河津禹门口(今称龙门), 区间黄河干流长 $723 \mathrm{~km}$, 河 谷陡峭狭窄, 河段宽 400 600 m, 峡谷水系切人黄土高原基岩平均深度约为 $170 \mathrm{~m}$. 晋陕峡谷河段干流落差 达 $617 \mathrm{~m}$, 河道坡降 $1.02 \%$, 水力资源丰富. 峡谷沿途发育大量支流, 峡谷东侧主要为偏关河、县川河、屈产 河、昕水河和湫水河等; 峡谷西侧主要有窟野河、秃尾河、无定河、清涧河和延河，区间支流众多、河网密集， 加上纵横交错的小支流和支沟形成了树枝状水系. 晋陕峡谷流域集水面积占黄河流域总面积的 $14.8 \%$, 属 于典型的温带季风气候, 其年平均降水量在 300 500 $\mathrm{mm}$ 之间, 从东南向西北递减. “伏秋大汛” 发生在 79 月.

在乡韩大桥下游方向的龙门水文站设于 1934 年,其距河口 $1269 \mathrm{~km}$,距上游壸口约为 $65 \mathrm{~km}$, 控制流域 面积为 $49.8 \times 10^{4} \mathrm{~km}^{2}$, 为黄河干流主要控制站. 年平均径流量为 $275.8 \times 10^{8} \mathrm{~m}^{3}$, 多年平均输沙量为 $8.01 \times 10^{8} \mathrm{t}$. 龙门站实测最大洪峰流量为 $21000 \mathrm{~m}^{3} / \mathrm{s}$ ( 1967 年 8 月 11 日), 最大含沙量为 $1040 \mathrm{~kg} / \mathrm{m}^{3}$ ( 2002 年), 多年年 均含沙量为 $29.0 \mathrm{~kg} / \mathrm{m}^{3}$. 历史调查最大洪水出现在道光年间 (1820-1850 年), 最大洪峰流量为 31000 $\mathrm{m}^{3} / \mathrm{s}^{[5]}$.

\section{2 古洪水 SWD 地层与研究方法}

\section{1 古洪水 SWD 沉积地层}

野外考察当中, 我们在晋陕峡谷多个沿河地点发现含有全新世古洪水滞流沉积层的剖面, 本文选择乡 韩桥 (XHQ) 地点进行重点研究. 该地点位于龙门水文站上游 $10 \mathrm{~km}$ 处, 沉积物剖面处于黄河右岸, 由于该地 点位于乡宁-韩城大桥附近, 故命名乡韩桥地点. 黄河壶口龙门段河道顺直规整, 河床冲淤变化很小, 为典型 的基岩河段,洪水期水位变化显著,适合进行古洪水水文学恢复研究. 由高水位滞流状态下堆积形成的古洪 水滞流沉积层赋存于河岸开阔回水湾的洪积台地上. 该洪积台地与平原河段由河床相与河漫滩相二元结构 的河流阶地有着极大的区别. 古洪水滞流沉积层夹杂坡积角砾石层, 保存完好, 分层清晰, 呈现水平或波状 层理, 与下伏的河床相沙层在颜色、粒度、结构等方面有着明显的区别. 根据沉积学原理, 整个沉积物剖面可 划分为 4 层 (SWD1 4), 是由古洪水在回水湾内滞流情况下沉积形成的, 每个单层的厚度在 $0.4 \sim 0.6 \mathrm{~m}$ 之 间, 为粉砂质细砂质地, 呈浊黄橙色, 各层之间沿层界横向裂开, 且各层界均由薄厚不一的坡积石渣土夹层 (图 1c). 这充分表明各洪水事件有一定的时间间隔,整个剖面记录了一期 4 次特大古洪水事件.

\section{2 研究方法}

黄河壶口至龙门段为典型的基岩峡谷河槽,规整的河道便于获取水文参数. 选取研究地点所在峡谷河 槽形态完整的河槽断面, 使用 Contour-XLR1-LC5279 型激光测距仪和高精度 GPS 测量断面形态, 并对古洪水 SWD 层厚度进行精确测量, 结果结合 $1: 10000$ 大比例尺地形图校正. 河道粘率系数值依据《天然河道糙率 表》进行选取.

采用“古洪水 SWD 厚度与含沙量法” 恢复古洪水洪峰水位 ${ }^{[6-9]}$. 古洪水洪峰流量推求采用 HEC-RAS (Hydrology Engineering Center-River Analysis System) 模型对 XHQ 河段进行一维恒定流河道水力推演, 从而 


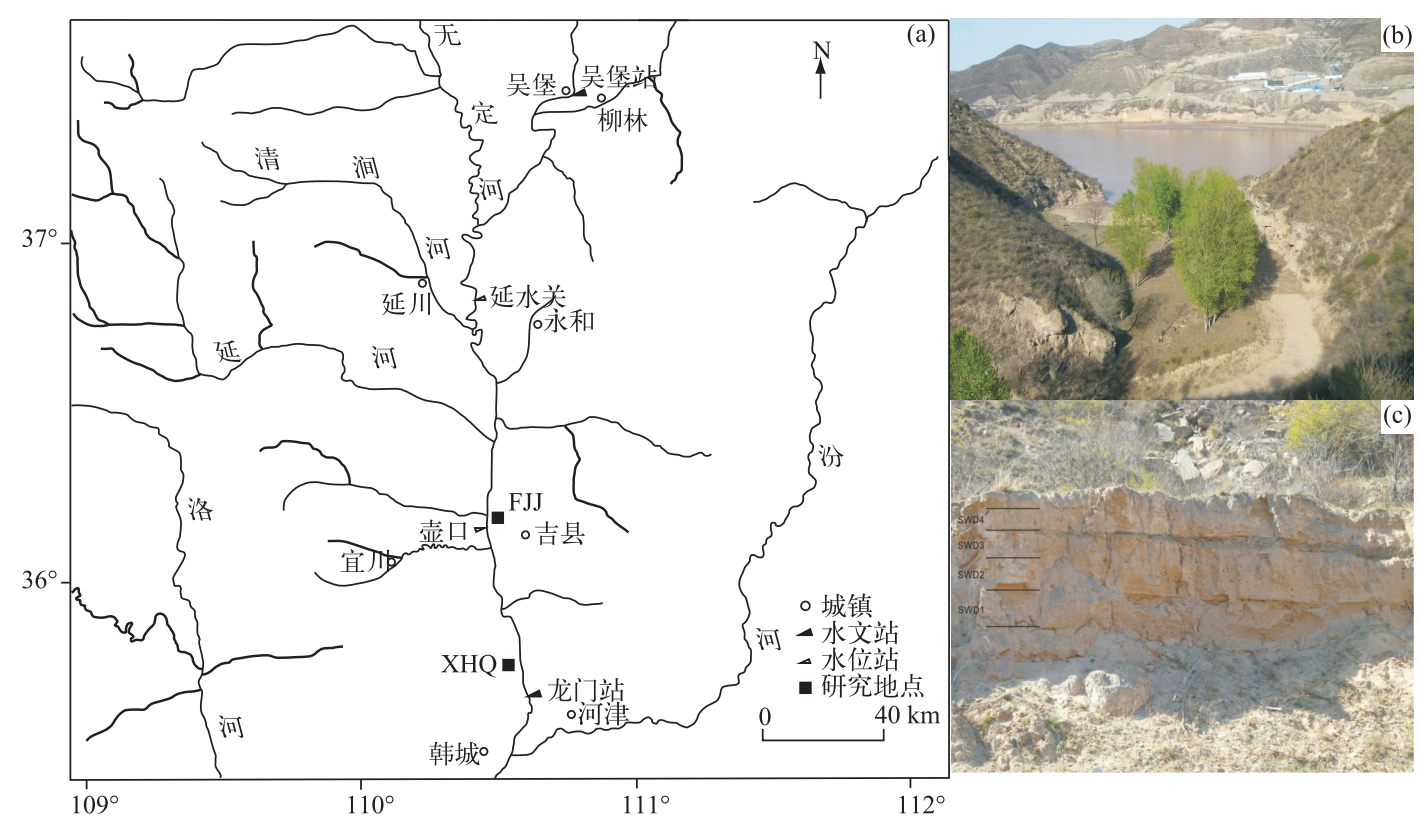

图 1 黄河晋陕峡谷段水系和乡韩桥 (XHQ)、冯家集 (FJJ) 研究剖面:

(a) 晋陕峡谷水系图; (b) XHQ 剖面位置; (c) XHQ 古洪水滞流沉积层

Fig.1 Location of the study XHQ site in the Jinshan Gorges of the Yellow River

模拟计算该河段全新世古洪水洪峰流量 ${ }^{[10-12]}$. 该模块采用水面曲线推流法,其计算原理基于一维恒定总流 能量方程:

$$
Y_{2}+Z_{2}+\frac{\alpha_{2} \cdot v_{2}^{2}}{2 \mathrm{~g}}=Y_{1}+Z_{1}+\frac{\alpha_{1} \cdot v_{1}^{2}}{2 \mathrm{~g}}+h e
$$

式中, $Y_{1} 、 Y_{2}$ 分别为断面水深, $Z_{1} 、 Z_{2}$ 分别为断面主河道高程, $v_{1} 、 v_{2}$ 分别为断面平均流速, $\alpha_{1} 、 \alpha_{2}$ 分别为流速系 数, $\mathrm{g}$ 为重力加速度, $h e$ 为水头损失.

HEC-RAS 模型是一个完整的软件系统, 可在多目标环境中交互使用 ${ }^{[10]}$. 首先在 ArcGIS 中数字化 XHQ 河段地形图,得到 TIN (不规则三角网); 在 ArcGIS 耦合的 HEC-GeoRAS 模块下概化所需几何资料(河岸线、 河流中心线、断面线等), 并将数据导人 HEC-RAS 模型下进行模拟. 在 HEC-RAS 软件中, 根据实地调查和量 测结果对断面进行修正, 并确定各水文参数. 模拟计算中, 与古洪水滞流沉积物洪峰水位最为贴合的水面线 (既最佳水面线), 其对应的流量值与水位值即为古洪水洪峰流量值与洪峰水位值.

将野外采集的沉积样品经前处理后进行室内磁化率、粒度成分分析, 以及古洪水 SWD 的鉴别. 磁化率 采用英国 Bartington 公司生产的 MS-2 型磁化率仪来测定. 粒度分析则采用美国 Beckman coulter 公司生产的 LS 13320/ULM 2 型激光粒度仪进行测定. 野外考察期间, 清理剖面表层 $10 \mathrm{~cm}$ 已曝光部分, 采用不锈钢管垂 直于 XHQ 剖面在 SWD4、SWD3、SWD2、SWD1 顶部和下伏沙层顶部采得 OSL 测年样品. 实验室内剥离钢管 两侧 $2 \sim 3 \mathrm{~cm}$ 见光样, 用于测定 $U 、 T h 、 K$ 以及含水量, 确定样品的年剂量 $(U 、 T h 、 K$ 含量在中国原子能研究 院采用中子活化法测定); 将管中剩余部分分别用 $10 \%$ 盐酸和 30\%过氧化氢溶液进行溶蚀, 除去样品中碳酸 盐类和有机质, 并将样液反复洗涤至中性; 将湿篎法分离出的 $90 \sim 125 \mu \mathrm{m}$ 的样品在 $37^{\circ} \mathrm{C}$ 恒温条件下烘干. 对文中所用实验样品在室温条件下用 $35 \%$ 氢氟酸溶蚀 $40 \mathrm{~min}$, 再加人 $10 \%$ 盐酸去除氟化物沉淀, 最后用清 水洗至中性, 得到纯净石英颗粒 ${ }^{[13-15]}$. 对于石英颗粒的纯度用红外光辐照 (IR) 检测, 并制备样片测量等效剂 量值 (De). 释光样品 De 的测定采用丹麦 Ris Ø 公司生产的 TL/OSL-DA-20 全自动释光测年仪, 运用单片再 生剂量法 ( single-aliquot regenerative-dose protocol, SAR) 测定 ${ }^{[13]}$ (表 1 ). 
表 1 黄河晋陕峡谷 XHQ 剖面光释光测年数据

Tab.1 Summary of the dosimetry, equivalent dose and OSL ages in the XHQ profile of the middle Yellow River

\begin{tabular}{ccccccccc}
\hline 样品 & $\begin{array}{c}\text { 深度/ } \\
\mathrm{m}\end{array}$ & $\begin{array}{c}\mathrm{U} / \\
(\mathrm{mg} / \mathrm{kg})\end{array}$ & $\begin{array}{c}\mathrm{Th} / \\
(\mathrm{mg} / \mathrm{kg})\end{array}$ & $\begin{array}{c}\mathrm{K} / \\
\%\end{array}$ & $\begin{array}{c}\text { 含水量/ } \\
\%\end{array}$ & $\begin{array}{c}\text { 等效剂量/ } \\
\mathrm{Gy}\end{array}$ & $\begin{array}{c}\text { 剂量率/ } \\
(\mathrm{Gy} / \mathrm{ka})\end{array}$ & $\begin{array}{c}\text { 年龄/ } \\
\mathrm{ka}\end{array}$ \\
\hline XHQ-SWD4 & 0.3 & $2.01 \pm 0.10$ & $8.11 \pm 0.07$ & $1.84 \pm 0.21$ & 15.2 & $8.40 \pm 0.45$ & $2.78 \pm 0.18$ & $3020 \pm 250$ \\
XHQ-SWD3 & 0.9 & $2.27 \pm 0.09$ & $8.48 \pm 0.26$ & $1.81 \pm 0.05$ & 15.9 & $8.94 \pm 0.70$ & $2.80 \pm 0.06$ & $3200 \pm 260$ \\
XHQ-SWD2 & 1.2 & $2.25 \pm 0.12$ & $9.49 \pm 0.28$ & $1.85 \pm 0.05$ & 17.5 & $9.43 \pm 0.68$ & $2.84 \pm 0.06$ & $3320 \pm 250$ \\
XHQ-SWD1 & 1.8 & $2.25 \pm 0.12$ & $8.96 \pm 0.27$ & $1.70 \pm 0.05$ & 16.2 & $8.80 \pm 0.41$ & $2.70 \pm 0.06$ & $3250 \pm 170$ \\
\hline
\end{tabular}

\section{3 结果}

\section{1 沉积学分析}

粒度分析是作为 SWD 鉴别中的重要手段. 4 层 SWD 粒度成分以粉砂为主, 其中粗粉砂 $(16 \sim 63 \mu \mathrm{m})$ 比 重最大, 细粉砂 (2 16 $\mu \mathrm{m}$ ) 含量稍次之(图 2). 全新世古土壤颗粒以中细粉砂为主, 砂粒含量很少; 而河床 相沙层颗粒则以细砂为主, 粘粒和粉砂含量较少. 河床相沙层峰态较窄, 古土壤峰态属中等, 该组 SWD 峰态 很窄, 属于典型的河流沉积物频率曲线形态. 古洪水 SWD 沉积物主峰粒径处于 $0.06 \sim 0.07 \mathrm{~mm}$ 区间, 古土壤 主峰粒径区间为 $0.015 \sim 0.030 \mathrm{~mm}$, 河床相沙层主峰粒径区间则为 $0.35 \sim 0.40 \mathrm{~mm}$. 该组古洪水 SWD 频率曲 线主峰窄而高, 分选较好, 呈极正偏特征. 古洪水 SWD 与古土壤以及河床相沙层相比有着明显的不同.

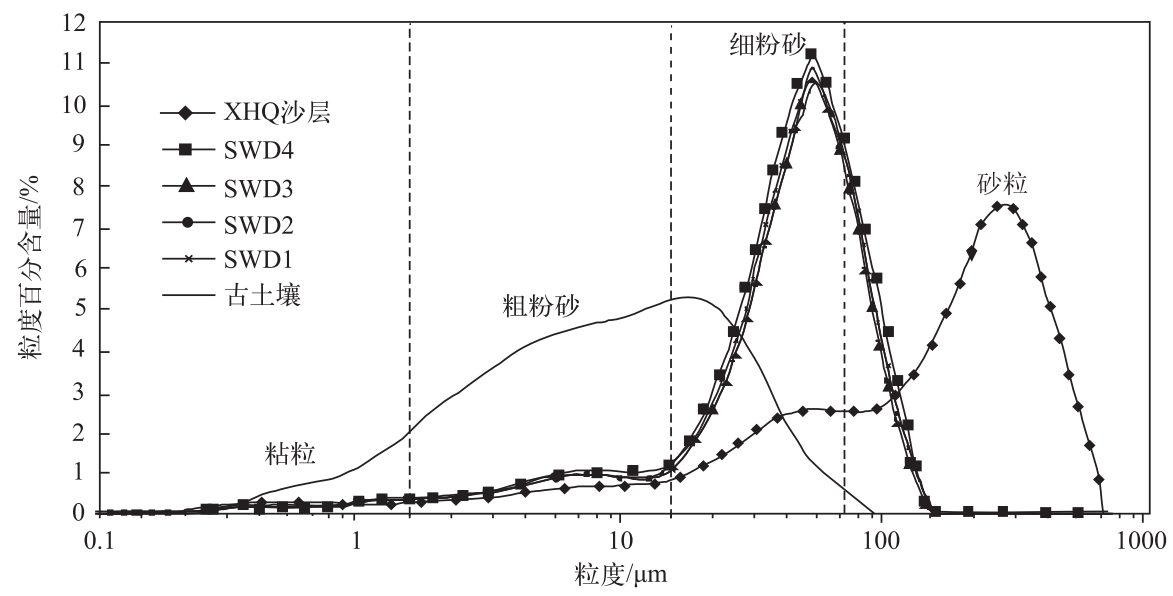

图 2 黄河 XHQ 剖面沉积物粒度分布频率曲线

Fig. 2 Distribution frequency curves of grain-size in the XHQ profile of the Yellow River

黄河晋陕峡谷 XHQ 剖面古洪水滞流沉积物的低频磁化率处于 $32.5 \times 10^{-8} \sim 35.2 \times 10^{-8} \mathrm{~m}^{3} / \mathrm{kg}$ 之间; 古土 壤磁化率最高, 为 $159.8 \times 10^{-8} \mathrm{~m}^{3} / \mathrm{kg}$; 河床相沙层磁化率最低, 为 $25.8 \times 10^{-8} \mathrm{~m}^{3} / \mathrm{kg}$. 该组古洪水 SWD 烧失量 在 $0.53 \% \sim 0.71 \%$ 之间变化, 波动较小, 而古土壤的烧失量相对较高. SWD 中碳酸钻含量的平均值为 $6.06 \%$, 河床相沙层含量最低, 为 $3.7 \%$ (表 2 ).

\section{2 年代确定}

对于晋陕峡谷 XHQ 地点全新世古洪水滞流沉积物, 采用 OSL 技术测年, 确定这 4 层 SWD 的沉积年龄 从下向上依次为 $3250 \pm 170 、 3320 \pm 250 、 3200 \pm 260$ 和 $3020 \pm 250 \mathrm{a}$ (图 3, 表 1). 我们的重点是对 SWD 进行光释 光年龄的测定, 进而确定 SWD 年代, 但其底部阶地河漫滩沙层样品的光释光年龄偏小, 予以舍弃, 这并不影 响对古洪水沉积年代框架的建立. 由于 4 层 SWD 层理连续, 各层夹杂的坡积物厚度很薄, 所以可以判定这 是一期 4 次的特大洪水事件, 且各次洪水事件发生时间间隔不长. 由于与渭河城东村 (CDC)、黄河並口段 FJJ 
表 2 黄河 XHQ 剖面全新世古洪水滞流沉积层沉积物理化指标

Tab.2 Analytical results between the flood SWD in the XHQ profile of the Yellow River

\begin{tabular}{ccccc}
\hline 地层层位 & 磁化率 $/\left(\times 10^{-8} \mathrm{~m}^{3} / \mathrm{kg}\right)$ & 烧失量 $/ \%$ & 碳酸䥻 $/ \%$ & 粘粒 $/$ 粉砂 \\
\hline SWD4 & 35.2 & 0.53 & 6.16 & 0.069 \\
SWD3 & 32.5 & 0.66 & 6.06 & 0.067 \\
SWD2 & 34.5 & 0.71 & 5.92 & 0.071 \\
SWD1 & 35.0 & 0.70 & 6.10 & 0.071 \\
古土壤 & 159.8 & 3.14 & 4.60 & 0.112 \\
河床相沙层 & 25.8 & 0.49 & 3.70 & 0.124 \\
\hline
\end{tabular}

地点的沉积地层和流域自然地理背景相似, 故将其与黄河 XHQ 地点进行地层对比, 再依据 OSL 测年结果, 确定 XHQ 剖面古洪水 SWD 是由发生在 3200-2800 a B.P. 之间的特大洪水滞流沉积而形成的, 这期古洪水 事件对应全新世中期温暖湿润期向全新世晚期干旱期转折阶段. 此时, 全新世大暖期彻底结束, 一个新的黄 土堆积期俨然开始. 同时, 我们在黄河晋陕峡谷壹口段 ${ }^{[16]}$ 、永和关段 ${ }^{[6]}$, 渭河河谷 ${ }^{[17]}$ 、汉江上游河谷 ${ }^{[18]}$ 也都 找到了发生在该时段的特大洪水事件的沉积学证据. 3200-2800 a B.P.对应着我国历史上商末-西周初期 的气候恶化转折阶段, 根据历史文献记载, 商朝末年干旱灾害加剧, 河水断流、沙尘暴频发、洪水泛滥、粮食 歉收、饥荒等等, 造成商末社会动乱和朝代更替 ${ }^{[19]}$. 在此气候恶化和波动转折期, 黄河中游流域季风状态失 稳, 气候和降水变率增大, 导致区域内大洪水和严重干旱事件皆有发生. 而来自我国其他地区以及世界范围 内的高分辨率研究也表明此时期是一个严重的全球性气候恶化期 ${ }^{[20-25]}$. 这些结果一方面证明了我们对 $\mathrm{XHQ}$ 地点古洪水事件断代的可靠性, 另一方面证明了这一期 4 次古洪水事件是黄河中游区域水文系统对于 全球变化规律响应的结果.

\section{4 古洪水水文学重建}

\section{1 古洪水洪峰水位和过水断面的确定}

对于黄河晋陕峡谷野外考察过程中, 依据古洪水 SWD 判别标准, 发现 XHQ 地点在支流沟口比较开阔 回水湾内赋存的沉积地层完全具备古洪水 SWD 的基本特征; 再结合室内沉积物理化测试分析结果, 更进一 步确认了其沉积学性质特点 ${ }^{[26]}$. 精确测量各层 SWD 厚度, 为水文重建提供基础.

在确定古洪水洪峰水位时, 国内外专家学者通常简单地采用古洪水 SWD 顶面高程值或者尖灭点高程 值作为古洪水最低洪峰水位值 ${ }^{[1-4]}$, 从而推求最小洪峰流量. 黄河中游干支流河网稠密, 黄土层深厚、土质疏 松、地形破碎、沟壀纵横、植被稀少, 且暴雨集中、强度大, 水土流失极为严重, 因此河流含沙量极高, 在该地 区计算全新世古洪水水位时, 运用 “古洪水 SWD 沉积厚度与含沙量法” 来确定洪峰水位, 结合精确测量的 每层 SWD 厚度与底界高程, 并估算古洪水体积含沙量, 求出 SWD 沉积水深, 该层古洪水 SWD 底界高程值 加上相应的沉积水深值便得到了该次古洪水事件的洪峰水位值 ${ }^{[-9]}$.

XHQ 剖面位于距离黄河干流附近的支沟口内 ( 图 1b), 该洪积台地 (flood bench) ${ }^{[2]}$ 是由黄河特大洪水 在高水位滞流状态下, 洪水倒灌进人支流沟口, 在河道边缘洪水位附近由悬移质沉积物反复多次堆积形成 的. 因此, 支流沟口 SWD 的高度可以作为干流古洪水水位的保守估计 ${ }^{[3]}$. XHQ 地点古洪水悬移质体积含沙 量为 $17 \%{ }^{[27]}$. 由此, 推定这一组 4 次古洪水 SWD 沉积水深介于 $2.35 \sim 3.53 \mathrm{~m}$, 古洪水洪峰水位高程介于 407 . 53 408.14 $\mathrm{m}$ ( 图 4、5).

国内外古洪水水文学界认为,基岩峡谷河段是进行古洪水水文学研究的理想河段 ${ }^{[3-4]}$. 黄河中游晋陕峡 谷段是典型的基岩峡谷, 岩层硬度大, 河道稳定、规则, 在全新世期间变化较小, 属于平衡断面, 这为水文学 研究的可靠性提供保证.

\section{2 古洪水洪峰流量模拟结果}

利用 HEC-RAS 模型推求古洪水洪峰流量时, 必须先确定模型所需的各项水文参数. 天然河道䊁率是衡 量河床及边壁形状的不规则和粗糙程度对水流运动影响的一个综合性系数, 因河床、岸壁的粗粘程度, 河道 
黄河中游XHQ剖面

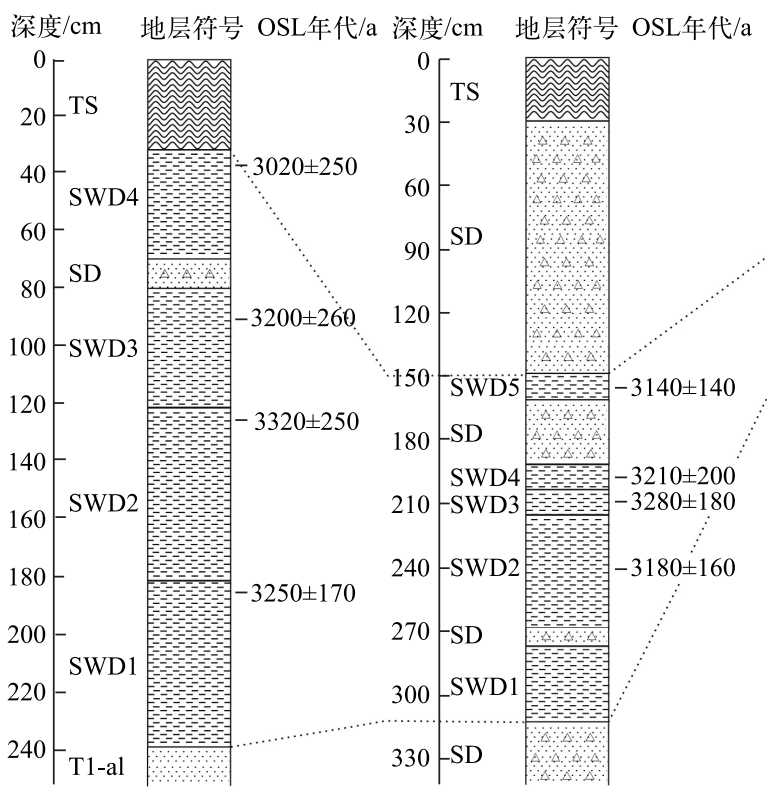

渭河中游 $\mathrm{CDC}$ 剖面

深度 $/ \mathrm{cm}$ 地层符号 OSL年代/a 校正年龄/a B.P.

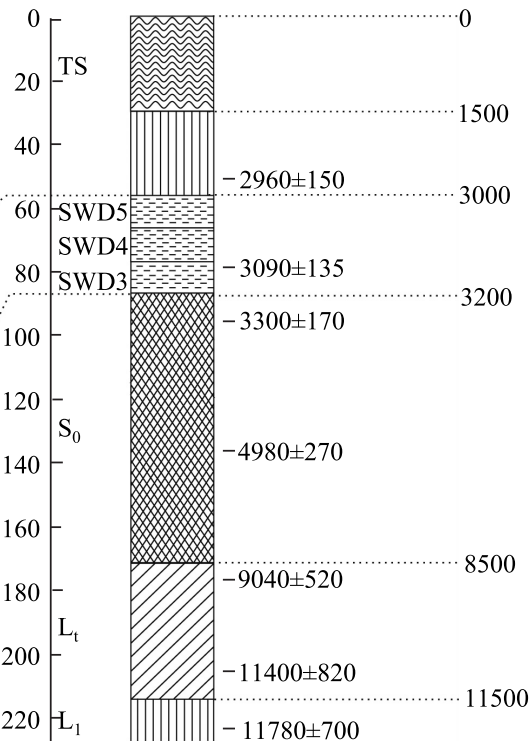

11500

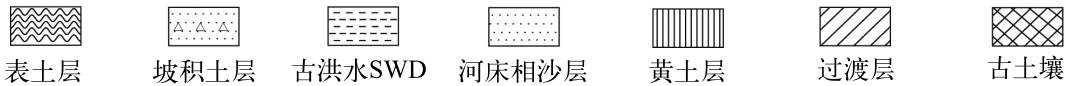

图 3 黄河 XHQ 全新世古洪水沉积剖面与黄河 FJJ 剖面以及渭河陈东村 (CDC) 剖面对比

Fig. 3 Pedo-stratigraphy and chronology in the XHQ profile and the correlation to the

Holocene loess-palaeosoil profiles in the middle reach of the Yellow River and the Weihe River

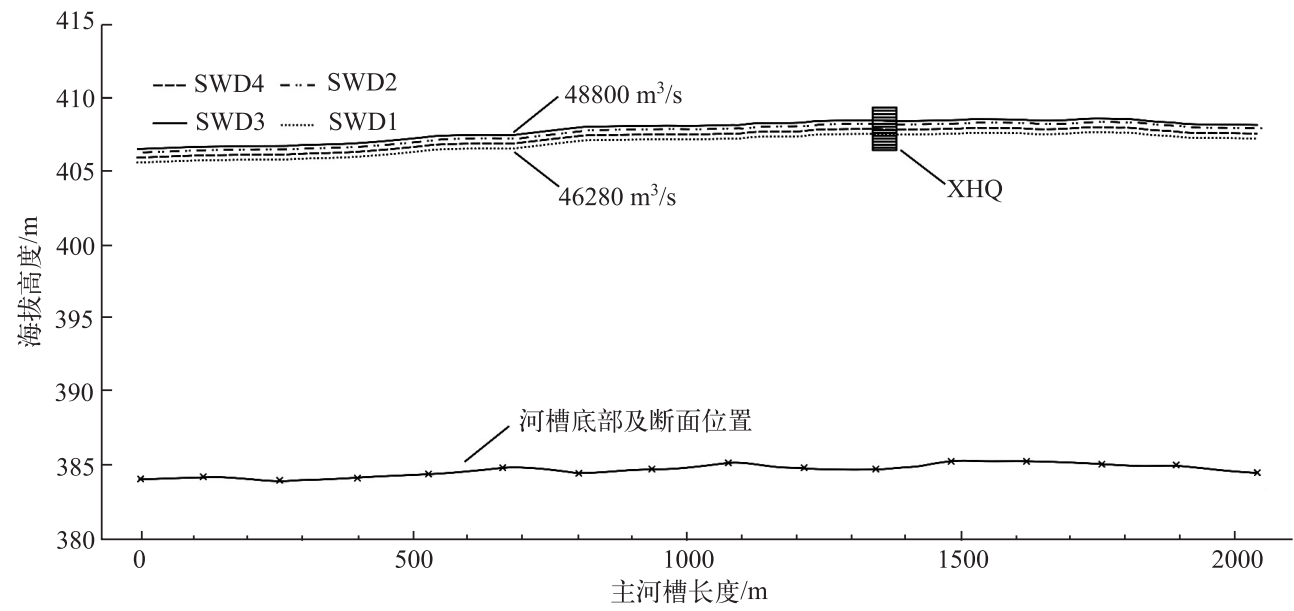

图 4 基于 HEC-RAS 模型模拟的黄河 XHQ 河段古洪水水面线

Fig.4 Calculated flood-surface profiles based on HEC-RAS model in the XHQ profile of the Yellow River

过水断面形状、大小和底坡沿程变化, 床面、岸壁地质特性, 水流流态及含沙量等的不同而不同 ${ }^{[28-29]}$. 黄河 XHQ 剖面河床为卵石, 石块, 水行于深槽峡谷间, 断面规整, 水声较大, 两侧岸壁为岩石, 崎岖不平整, 上面生 长杂草、树木. 当发生特大洪水时,水流可将全部河槽淹没. 在全新世时期基岩河槽变化很小,结合该河段的 


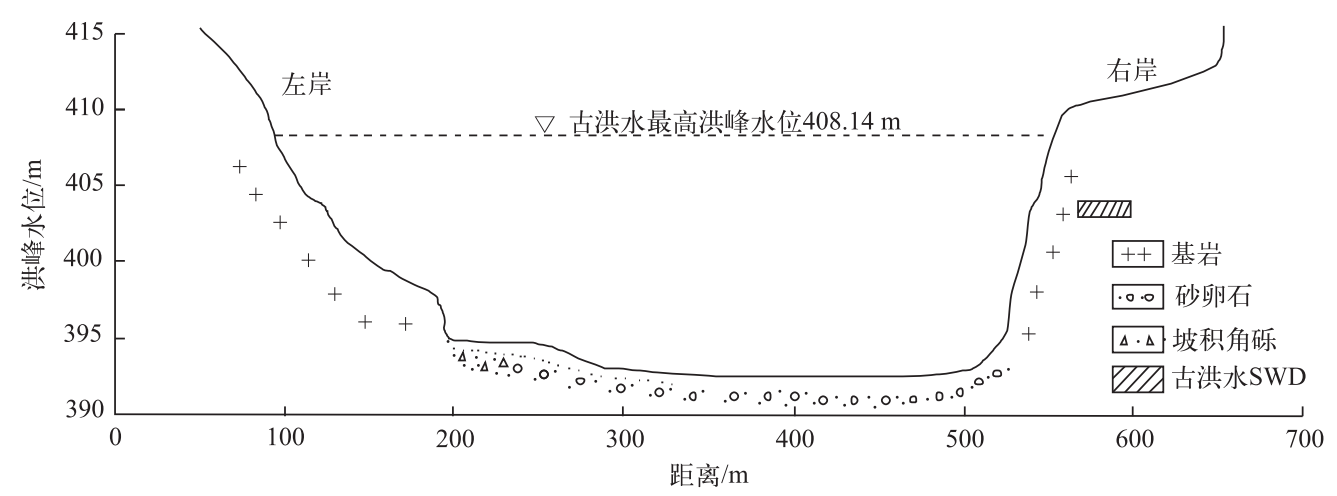

图 5 黄河 XHQ 河段河槽断面地质地貌特征与古洪水洪峰水位

Fig.5 Cross-section of the channel and the palaeoflood peak stage at the XHQ section of the Yellow River

地表特征, 根据䊁率表所描述天然河道的特征 ${ }^{[28]}$, 以及前人在研究区域进行水文调查的经验值, 结合野外所 见各断面所处河段特征和当时河流沿岸植被覆盖状况得到研究断面河道粘率值, XHQ 所属类型为 V 类, 主 河槽糙率系数 $n$ 值为 0.035 , 左右岸 $n$ 值为 0.040 .

收缩系数与扩张系数用来评估河道收缩和扩张的能量损失. XHQ 河段水流属缓流状态, 河槽是逐渐收 缩与扩张的,参考 HEC-RAS v4.1 的 Reference Manual, 收缩系数和扩张系数取值分别为 0.1 和 $0.3^{[10]}$.

一般来说, 能量坡降几乎可以用河道坡降或水面比降来代替 ${ }^{[10]}$. 在确定 XHQ 河道比降时, 由于黄河中 游晋陕峡谷段较顺直, 河床为基岩, 全新世大暖期以来受冲刷和淤积影响小, 且河槽稳定, 因此以河床比降 代替水面比降 ${ }^{[10]}$. 水面比降是指河道的水面两点间落差与其长度的比值. 野外考察时用 GPS 和红外线测距 仪精确测量高程和距离, 并在室内用 $1: 10000$ 地形图进行校正, 得到符合实际情况的水面比降, 本文计算得 到 XHQ 水面比降为 0.001 .

应用 HEC-RAS 模型进行古洪水模拟, 在黄河中游龙门段 $3 \mathrm{~km}$ 长的河段上均匀选取 16 个过水断面 (图 6), 并确定相关参数, 进行洪水流量计算. 在一维恒定流模型中给定不同流量进行试算, 对比水面线与古洪 水 SWD 指示洪峰水位的关系, 得到黄河中游 XHQ 地点一期 4 次古洪水 SWD 记录的全新世特大洪水洪峰流 量介于 $46280 \sim 48800 \mathrm{~m}^{3} / \mathrm{s}$ (图 4).

\section{3 模型可靠性检验}

在利用 HEC-RAS 模型推求古洪水洪峰流量的过程中, 河道粘率系数的选取对于模拟结果的影响度很 大. 所以, 我们在野外实地勘察中, 对该河段的河道形态、河床质成分、植被覆盖度、人类活动影响和水流形 态特征等方面进行分析研究, 并借鉴天然河道糙率问题的前沿成果 ${ }^{[30-31]}$, 合理慎重选取 $n$ 值. 同时, 在洪水 模拟过程中, 设定其他水文参数保持不变, 给定粘率系数 $\pm 25 \%$ 变率, 进行鋉率系数灵敏度测验. 结果表明各 自对应的洪峰流量变幅在-10.88\% 7.85\% 之间 (表 3). 若使用传统的比降-面积法计算洪峰流量, 由公式 (2) 可知, 粘率系数 $n$ 的选取对 $Q$ 值影响更大. 所以, 利用 HEC-RAS 模型进行古洪水洪峰流量恢复所得结果 更为精确.

$$
Q=\frac{1}{n} A \cdot R^{\frac{2}{3}} \cdot S^{\frac{1}{2}}
$$

式中, $A$ 为过流断面面积 $\left(\mathrm{m}^{2}\right), Q$ 为洪峰流量 $\left(\mathrm{m}^{3} / \mathrm{s}\right), n$ 为河道糙率系数, $R$ 为水力半径 $(\mathrm{m}), S$ 为水面比降.

从在泾河 ${ }^{[7]}$ 、北洛河 ${ }^{[8]}$ 、渭河 ${ }^{[32]}$ 、汉江上游 ${ }^{[33-34]}$ 等多个地点恢复的古洪水洪峰流量结果来看, 在全新世 时期发生特大洪水事件的最大洪峰流量不超过水文观测记录的 4.5 倍 ${ }^{[6]}$. 结合 XHQ 地点附近的龙门水文站 水文观测记录, 以及洪水洪峰流量与流域面积关系的研究 ${ }^{[2]}$, 表明运用 HEC-RAS 模型进行古洪水水文恢复 计算的结果是可靠的. 


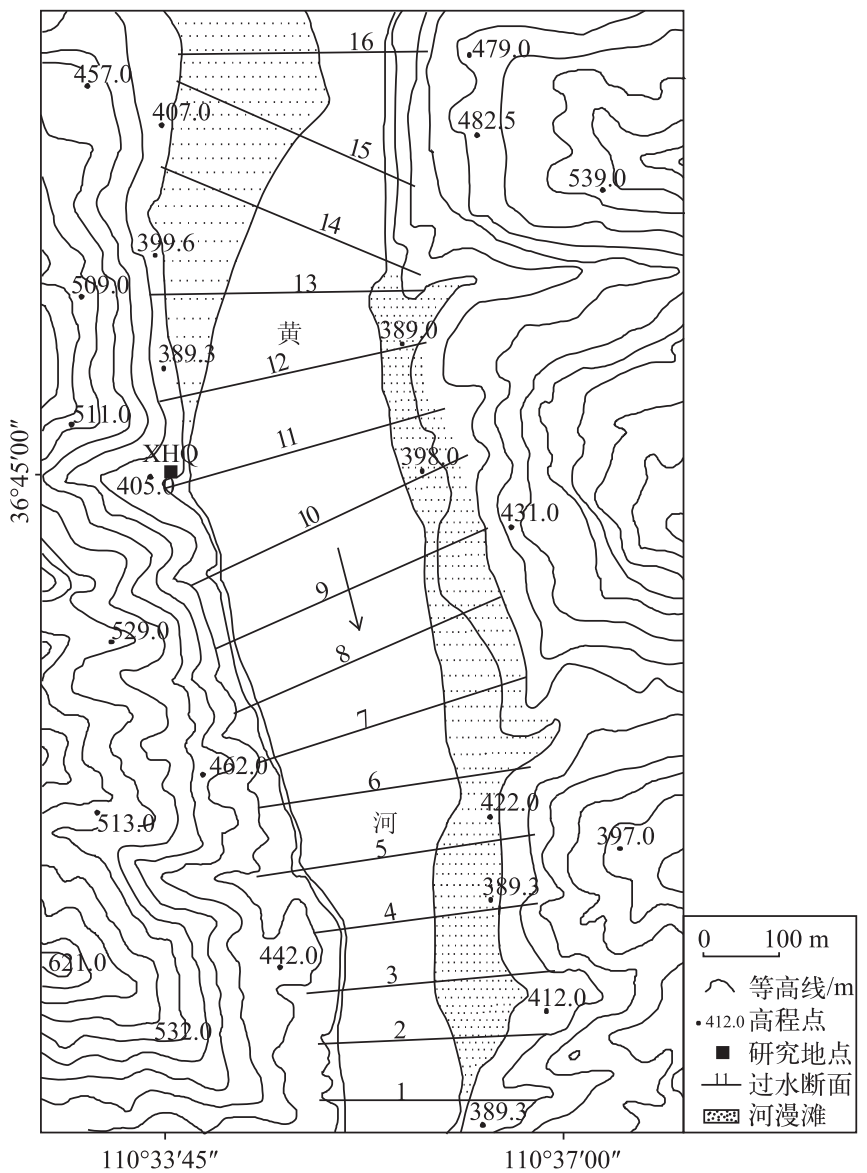

图 6 黄河龙门段乡韩桥 (XHQ) 河段和河槽断面系列位置

Fig.6 Location of the studied site and the cross-section in the Longmen reach of the Yellow River

表 3 黄河 XHQ 河段全新世古洪水糙率系数的灵敏度测试结果

Tab.3 Results of the sensitivity test performed on the hydraulic calculations in the XHQ reach of the Yellow River

\begin{tabular}{|c|c|c|c|c|c|}
\hline \multirow{2}{*}{ 古洪水事件 } & \multicolumn{3}{|c|}{ 洪峰流量 $Q /\left(\mathrm{m}^{3} / \mathrm{s}\right)$} & \multicolumn{2}{|c|}{ 变幅/\% } \\
\hline & $n * 1.25$ & $n * 1.00$ & $n * 0.75$ & $n * 1.25$ & $n * 0.75$ \\
\hline SWD3 & 43490 & 48800 & 52630 & $-10.88 \%$ & $7.85 \%$ \\
\hline SWD4 & 43550 & 48770 & 52440 & $-10.70 \%$ & $7.53 \%$ \\
\hline SWD1 & 43300 & 48450 & 52190 & $-10.63 \%$ & $7.72 \%$ \\
\hline SWD2 & 41400 & 46280 & 49800 & $-10.54 \%$ & $7.61 \%$ \\
\hline
\end{tabular}

\section{5 古洪水事件发生的气候背景探讨}

特大洪水的发生与大气环流的异常有关, 而大气环流的异常又与气候变化关系密切. 全新世特大古洪 水事件往往发生在气候过渡时期的突变阶段, 是对气候极端事件即时性的响应. 在气候突变恶化阶段,降水 变率增大,会导致洪水事件的发生. 美国学者 Knox 指出全新世一万年以来洪水重现期与气候变化有一定的 相关性 ${ }^{[35-37]}$. 殷淑燕等 ${ }^{[38]}$ 统计分析汉江上游历史时期的洪水灾害资料, 发现汉江上游洪水发生频率与强度 在清后期至现代为最高时期,其次出现在明末清初和唐代末期,再次是西汉初期、明代初期. 这说明历史时 
期洪水灾害的出现同样与气候的异常波动有关. 不是简单地在气候湿润期较多,在暖干期变少,而是在气候 突变转型期、波动期的大背景下较多较强烈.

根据古洪水释光断代结果和地层学分析表明, 黄河晋陕峡谷龙门段 XHQ 剖面的一组 4 层古洪水滞流 沉积物所记录的古洪水发生在 3200-2800 a B.P.,这组古洪水发生在全新世中期温暖湿润期向全新世晚期 干旱期的转折阶段. 此时, 全新世大暖期彻底结束, 黄土堆积期重新开始. 我们在黄河中游晋陕峡谷段的若 干地点发现同一时期的古洪水滞流沉积物. 如吴堡水文观测站下游 $10 \mathrm{~km}$ 处的两河口(LHK) 地点发现一组 4 层古洪水滞流沉积层, 确定这 4 次洪水发生在 3200-3000 a B.P., 采用面积-比降法计算出洪峰流量介于 $41268 \sim 47415 \mathrm{~m}^{3} / \mathrm{s}$ 之间 ${ }^{[39]}$; 黄河中游永和关 (YHG) 剖面含有一组 5 层古洪水滞流沉积层, 确定这 5 次洪水 发生在全新世中期一晚期转折阶段, 即 3200-3000 a B.P., 采用面积-比降法计算出洪峰流量介于 $28380 \sim$ $48590 \mathrm{~m}^{3} / \mathrm{s}$ 之间 ${ }^{[6]}$; 黄河中游吉县段 FJJ 剖面含有一组 4 层古洪水滞流沉积层, 确定这 4 次洪水也发生在该 时期, 洪峰流量介于 $43290 \sim 49830 \mathrm{~m}^{3} / \mathrm{s}$ 之间 ${ }^{[40]}$. 同时, 我们在渭河河谷 ${ }^{[17]}$ 、汉江上游河谷 ${ }^{[18]}$ 、漆水河中 游 ${ }^{[41]}$ 等地点也都发现了该时段的特大洪水事件沉积学证据. 来自我国其他地区的高分辨率研究也记录了 这个气候恶化期. 云南宁莨石笋 $\delta^{18} \mathrm{O}$ 序列在 3200-2800 a B.P.期间呈现出由极低值向极高值的突变 ${ }^{[20]}$. 浙 江天目山泥炭 $\delta^{18} \mathrm{OC}_{\text {org }}$ 序列在 3200-2800 a B.P.期间呈波动降低,记录了气候多次冷暖变化 ${ }^{[21]}$. 贵州董哥 洞以及汉江上游神农架地区的多个洞穴石笋氧同位素记录表明该时段气候恶化且显著变冷 ${ }^{[22-23]}$. 而来自世 界范围内其他地区的高分辨率研究表明, 这段时期是一个全球性气候恶化期. 格陵兰 GISP2 冰芯 $\delta^{18} \mathrm{O}$ 和其 他气候代用指标当中,显示出气候显著变冷 ${ }^{[24]}$. 北大西洋海洋沉积记录的冰岛玻璃碎屑和赤铁矿锈斑含量 序列清楚地记录了此时期的气候突变事件 ${ }^{[25]}$. 这些证据都表明,在 3200-2800 a B.P.气候恶化期内,气候波 动变化、不稳定, 季风格局失稳, 降水变率增大, 旱涝频发. 这次气候恶化主要归结于太阳活动变化、大气环 流以及火山活动等 ${ }^{[36]}$. 这次气候恶化事件对当时的中国社会产生了较大的影响. 黄春长等认为 $3200-2800$ a B.P.正好对应我国历史上商末一西周时期,商朝末年气候恶化、洪水泛滥、旱灾和沙尘暴频发,造成农业歉 收和饥荒等,社会不稳定因素增加 ${ }^{[41-45]}$.

可见, 在全球性气候转折波动背景下, 黄河中游地区季风失稳, 气候变率增大, 干旱和洪水皆有发生, 气 候水文系统发生剧烈变化, 流域内植被显著退化, 影响暴雨径流的同时也增强了洪水过程. 对古洪水事件研 究发现, 古洪水发生在气候异常波动变化转折期, 这一发现对在全球变暖背景下研究现代洪水对气候变化 的响应方式作出指导; 同时, 掌握了长时间尺度特大或大洪水事件的发生规律和气候背景, 对于正确认识和 防治现代洪水尤其是现代大洪水的发生提供很好的科学依据. 文中研究河段历史时期极端洪水事件发生在 全球气候变化的背景之下,这一研究结果揭示了该区域河流水文系统对全球气候变化的响应,而包括河流 在内的全球水文系统也为全球变化研究的对象之一,故而,本研究结果丰富了全球变化的区域响应理论,推 动了气候变化理论的进步.

\section{6 结论}

通过对黄河中游开展广泛细致的古洪水水文学野外考察, 最终选择黄河龙门段 XHQ 地点全新世古洪 水滞流沉积物作为研究对象. 结合野外沉积学分析和室内实验室理化特征分析, 确定黄河龙门段右岸 XHQ 剖面的一组古洪水 SWD 为黄河特大洪水悬移质滞流沉积物.

运用 HEC-RAS 模型法对该研究河段进行古洪水水面线和洪峰流量模拟,推求出这一期 4 次古洪水流 量介于 $46280 \sim 48800 \mathrm{~m}^{3} / \mathrm{s}$. 通过粘率灵敏度测试发现, 此模型法可有效减小粘率系数对于计算结果的影响. 最大洪峰流量与流域面积对应关系也证明计算结果符合实际情况,是合理可信的.

根据地层对比和 OSL 测年数据, 确定了这期大洪水事件发生于 3200-2800 a B.P.. 这正是全新世大暖 结束、晚全新世现代黄土开始堆积的时段. 该气候恶化阶段季风气候失稳和气候变率增大,导致我国诸多流 域发生特大洪水事件. 这对于深人理解季风区域河流流域气候水文系统对于当前全球变化的响应规律具有 重要的科学意义.

\section{7 参考文献}

[ 1 ] Zhan Daojiang, Xie Yuebo eds. Palaeoflood study. Beijing: Water Resources and Hydropower Press, 2001: 1-83. [詹道 
江, 谢悦波. 古洪水研究. 北京: 中国水利水电出版社, 2001: 1-83.]

[ 2 ] Baker VR. Palaeoflood hydrology in a global context. Catena, 2006, 66( 1/2):161-168.

[ 3 ] Yang Dayuan, Xie Yuebo. Palaeoflood slack-water deposits. Acta Sedimentologica Sinca, 1997, 15(3): 29-32. [ 杨达源, 谢悦波. 古洪水平流沉积. 沉积学报, 1997, 15(3): 29-32.]

[ 4 ] Xie Yuebo, Jiang Hongtao. The Palaeoflood study-Digging the chronicle of the river floods. Journal of Nanjing University (Natural Sciences)，2001，37(3) : 390-394. [谢悦波, 姜洪涛. 古洪水研究一一挖掘河流大洪水的编年史. 南京大 学学报: 自然科学版, 2001, 37(3): 390-394.]

[ 5 ] Shi Fucheng, Yi Yuanjun, Mu Ping eds. The investigation research and study historical flood events' of the Yellow River. Zhengzhou: The Yellow River Water Conservancy, 2002: 81-123. [史辅成, 易元俊, 慕平. 黄河历史洪水调查考证和 研究. 郑州: 黄河水利出版社, 2002:81-123.]

[ 6 ] Huang Chunchang, Li Xiaogang, Pang Jiangli et al. Palaeoflood sedimentological and hydrological studies on the Yongheguan reach in the middle Yellow River. Acta Geographic Sinica, 2012, 67(11): 1493-1504. [黄春长, 李晓刚, 庞奖 励等. 黄河永和关段全新世古洪水研究. 地理学报, 2012, 67(11) : 1493-1504.]

[ 7 ] Li Yuqin, Huang Chunchang, Zha Xiaochun et al. Palaeoflood occurrence in the late period of the Longshan Culture in the middle reaches of the Jinghe River. Acta Geographica Sinca, 2009, 64(5): 541-542. [李瑜琴, 黄春长, 查小春等. 泾河 中游龙山文化晚期特大洪水水文学研究. 地理学报, 2009, 64(5): 541-542.]

[ 8 ] Yao Ping, Huang Chunchang, Pang Jiangli et al. Palaeoflood hydrological studies in the middle reaches of the Beiluohe River. Acta Geographica Sinica, 2008, 63(5) : 80-88. [姚平, 黄春长, 庞奖励等. 北洛河中游黄陵洛川段全新世古洪 水研究. 地理学报, 2008, 63(5):80-88.]

[ 9 ] Hu Guiming, Huang Chunchang, Zhou Yali et al. Hydrological reconstruction of Holocene palaeofloods and historical floods in the Longmen Gorge of the Yihe River. Acta Geographica Sinica, 2015, 70(7)：1165-1176. [胡贵明, 黄春长, 周亚利等. 伊河龙门峡段全新世古洪水和历史洪水水文学重建. 地理学报, 2015, 70(7): 1165-1176.]

[10] US Army Crops of Engineers HEC ed. HEC-RAS river analysis system hydraulic reference manual. Davis, California, USA, 2010.

[11] Chen Jianfeng, Wang Ying, Li Yang. Application of HEC-RAS model in simulation of flood. Water Resources \& Hydropower of Northeast China, 2006, (11) : 12-13. [陈建峰, 王颖, 李洋. HEC-RAS 模型在洪水模拟中的应用. 东北水利水 电, 2006, (11): 12-13.]

[12] Xue Xiaoyan, Zha Xiaochun, Huang Chunchang et al. Influence of channel roughness coefficient on the Holocene palaeoflood discharge calculation. Arid Land Geography, 2015, 38(20): 292-297. [薛小燕, 查小春, 黄春长等. 河道粘率系 数变化对全新世古洪水流量计算的影响研究. 干旱区地理, 2015, 38(20): 292-297.]

[13] Murray AS, Wintle AG. Luminescence dating of quartz using an improved single-aliquot regenerative-dose protocol. Radiation Measurements, 2000, 32(1): 57-73.

[14] Lai ZP, Zhang WG, Chen X et al. OSL chronology of loess deposits in East China and its implications for East Asian monsoon history. Quaternary Geochronology, 2010, 5: 154-158.

[15] Fuchs M, Lang A. OSL dating of coarse-grain fluvial quartz using single-aliquot protocols on sediments from NE Peloponnese, Greece.Quaternary Science Reviews, 2001, 20: 783-787.

[16] Li Xiaogang, Huang Chunchang, Pang Jiangli et al. Hydrological studies of the Holocene Palaeoflood in the Hukou Reach of the Yellow River. Acta Geographica Sinica, 2010, 65(11): 1371-1380. [李晓刚, 黄春长, 庞奖励等. 黄河壸口段全 新世古洪水事件及其水文学研究. 地理学报, 2010, 65(11): 1371-1380.]

[17] Wang Hengsong, Huang Chunchang, Zhou Yali et al. OSL dating of the Holocene Palaeoflood Events: A case study of the Lintong segment in the Lower Weihe River Valley. Acta Geoscientica Sinica, 2012, 33(2) : 227-235. [王恒松, 黄春长, 周亚利等.全新世古洪水事件光释光测年研究——以渭河下游临潼段为例. 地球学报, 2012, 33(2): 227-235.]

[18] Xu Jie, Huang Chunchang, Pang Jiangli et al. Sedimentological and hydrological studies of the palaeoflood events in the Ankang esat section in the upper reaches of the Hanjiang River. J Lake Sci, 2013, 25(3) : 445-454. DOI: 10.18307/ 2013.0320. [许洁, 黄春长, 庞奖励等. 汉江上游安康东段全新世古洪水沉积学与水文学研究. 湖泊科学, 2013, 25(3) : 445-454.]

[19] Huang CC, Su HX. Climate change and Zhou relocations in early Chinese history. Journal of Historical Geography, 2009, 35(2) : 297-310. 
[20] Zhang Meiliang, Lin Yushi, Zhu Xiaoyan et al. The Stalagmite records of the late Holocene in Ninglang of Yunnan. Marine Geology \& Quaternary Geology, 2006, 26(1) : 35-40. [ 张美良, 林玉石, 朱晓燕等. 云南宁蒗地区中全新世晚期气候 变化的石笋记录. 海洋地质与第四纪地质, 2006, 26(1) : 35-40.]

[21] Yang Guifang, Huang Junhua, Xie Shucheng et al. Qrganic carbon isotopic characteristics and their paleoenvironmental implications: A case study of the Tianmushan Peat Bog. Acta Geoscientica Sinca, 2008, 29(6) : 778-782. [杨桂芳, 黄俊 华, 谢树成等. 天目山泥炭有机碳同位素特征及其古环境意义. 地球学报, 2008, 29(6): 778-782.]

[22] Dong Jinguo, Kong Xinggong, Wang Yongjin et al. The east Asian monsoon climate changes at mt. Shennongjia and its relation to shift of intertropical convergence zone during the Holocene. Quaternary Research, 2006, 26(5) : 821-832. [ 董进 国, 孔兴功, 汪永进等. 神农架全新世东亚季风演化及其热带辐合带控制. 第四纪研究, 2006, 26(5): 821-832.]

[23] Wang YY, Cheng H, Edward RL. The Holocene Asian monsoon: Links to solar changes and North Atlantic climate. Science, 2005, 308: 854-857.

[24] Meeker DA, Gow AJ, Grootes P et al. The accumulation record from the GISP2 core as an indicator of climate change throughout the Holocene. Science, 1994, 266: 257-266.

[25] Bond G, Showers W, Cheseby M et al. A pervasive millennial scale cycle in North Atlantic Holocene and glacial climates. Science, 1997, 278: 1257-1266.

[26] Wang Xiaqing, Huang Chunchang, Pang Jiangli et al. Holocene palaeoflood slackwater deposits in the Hukou-Longmen Reach of the Yellow River. Chinese Journal of Soil Science, 2011, 42(4) : 781-786. [王夏青, 黄春长, 庞奖励等. 黄河 壶口至龙门段全新世古洪水滞流沉积物研究. 土壤通报, 2011, 42(4) : 781-786.]

[27] Xu Jianhua, Li Xiaoyu, Chen Jianjun et al eds. Effects of engineering on storm rains and floods in the middle reaches of the Yellow River: The Hukou to Longmen part. Zhengzhou: Yellow River Conservancy Press, 2009: 1-340. [徐建华, 李 晓宇, 陈建军等. 黄河中游河口镇至龙门区间水利水保工程对暴雨洪水泥沙影响研究. 郑州: 黄河水利出版社, 2009: 1-340.]

[28] Wuhan institute of hydraulic and electric engineering, hydraulics teaching and research section ed. Hydraulics. Beijing: Higher Education Press, 1986: 335-336. [武汉水利电力学院水力学教研室. 水力学. 北京: 高等教育出版社, 1986: 335-336.]

[29] Bureau of hydrology, Yangtze valley planning office ed. Hydrological academic discussion papers anthology. Guiyang: Guizhou People's Publishing House, 1983. [ 长江流域规划办公室水文局. 水文测验学术讨论论文选集. 贵阳: 贵州 人民出版社, 1983.]

[30] Zhang Xiaoqin, Bao Weimin, Liang Wenqing et al. Recent studies and progresses of the river roughness. Water Power, 2008, 34(6) : 98-100. [张小琴, 包为民, 梁文清等. 河道粘率问题研究进展. 水力发电, 2008, 34(6): 98-100.]

[31] Shi Bing, Wang Chuanyuan, Yin Zegao et al. Effect of vegetation submerged in river on the roughness coefficient. Periodical of Ocean University of China, 2009, 39(2) : 295-298. [拾兵, 王川源, 尹则高等. 淹没植物对河道鋉率的影响. 中国海洋大学学报, 2009, 39 (2) : 295-298.]

[32] Wan Honglian, Huang Chunchang, Pang Jiangli et al. Holocene extreme floods of the Baoji Gorges of the Weihe River. Quaternary Science, 2010, 30(2) : 430-440. [万红莲, 黄春长, 庞奖励等. 渭河宝鸡峡全新世特大洪水水文学研究. 第四纪研究, $2010,30(2): 430-440$. ]

[33] Zha Xiaochun, Huang Chunchang, Pang Jiangli et al. The Holocene Palaeoflood events in the Yunxi Reach in the upper reaches of Hanjiang River. Acta Geographica Sinca, 2012, 67(5): 97-106. [查小春, 黄春长, 庞奖励等. 汉江上游郧 西段全新世古洪水事件研究. 地理学报, 2012, 67(5): 97-106.]

[34] Liu Tao, Huang Chunchang, Pang Jiangli et al. Extraordinary hydro-climatic events during 1800-1600 yr BP in the JinShaan Gorges along the middle Yellow River, China. Palaeogeography, Palaeoclimatology, Palaeoecology, 2014,410 (11) : 143-152.

[35] Knox JC. Responses of floods to Holocene climatic change in the Upper Mississippi Valley. Quaternary Research, 1985, 23: 287-300.

[36] Knox JC. Extreme hydrological events, palaeo-information and climate change. Hydrological Sciences, 1997, 42( 5): 765.

[37] Knox JC. Sensitivity of modern and Holocene floods to climate change. Quaternary Science Reviews, 2000, 19: 439-457.

[38] Yin Shuyan, Wang Haiyan, Wang Deli et al. Study on historical flood disasters and climate change in the upper reaches of the Hanjiang River. Arid Zone Research, 2010, 27(4) : 522-528. [殷淑燕, 王海燕, 王德丽等. 陕南汉江上游历史洪 
水灾害与全球气候变化. 干旱区研究, 2010, 27(4): 522-528.]

[39] Fan LJ, Huang CC, Pang JL et al. Sedimentary records of palaeofloods in the Wubu Reach along the Jin-Shaan Gorges of the middle Yellow River, China. Quaternary International, 2014, 380/381: 368-376.

[40] Li XG, Huang CC, Pang JL et al. Sedimentary and hydrological studies of the Holocene palaeofloods in the Shanxi-Shaanxi Gorge of the middle Yellow River, China. Int J Earth Sci(Geol Rundsch), 2015, 104: 277-288.

[ 41] Huang CC, Pang JL, Zha XC et al. Extraordinary floods related to the climatic event at 4200 a BP on the Qishuihe River, middle reaches of the Yellow River, China. Quaternary Science Reviews, 2007, 26: 2247-2264.

[42] Briffa KR. Annual climate variability in the Holocene: Interpreting the message of ancient trees. Quaternary Science Reviews, 2000, 39(2) : 166-176.

[43] Wang Hui, Huang Chunchang. The change of climate and environment in the middle valley of the Yellow River at the end of the Shang Dynasty and social change. Journal of Historical Science, 2002, (1):13-18. [王晖, 黄春长. 商末黄河中游 气候环境的变化与社会变迁. 史学月刊, 2002, (1):13-18.]

[44] Huang CC, Zhao XC, Pang JL et al. Climatic aridity and the relocations of the Zhou Culture in the Southern Loess Plateau of China. Climate Change, 2003, 61(3) : 361-378.

[45] Huang Chunchang, Pang Jiangli, Zha Xiaochun et al. Prehistorical floods in the Guanzhong Basin in the Yellow River drainage area: A case study along the Qishuihe River Valley over the Zhouyuan loess tableland. Science China: Earth Science, 2011, 41(11) : 1658-1669. [ 黄春长, 庞奖励, 查小春等. 黄河流域关中盆地史前大洪水研究: 以周原漆水河 谷底为例. 中国科学: 地球科学, 2011, 41(11): 1658-1669.] 